\title{
Bacteroides coprosuis sp. nov., isolated from swine-manure storage pits
}

\author{
Terence R. Whitehead, ${ }^{1}$ Michael A. Cotta, ${ }^{1}$ Matthew D. Collins, ${ }^{2}$ \\ Enevold Falsen ${ }^{3}$ and Paul A. Lawson ${ }^{4}$
}

Correspondence

Terence R. Whitehead

whitehtr@ncaur.usda.gov

\author{
${ }^{1}$ Fermentation Biotechnology Research Unit, National Center for Agricultural Utilization \\ Research, USDA, Agricultural Research Service, 1815 N. University Street, Peoria, IL 61604, \\ USA \\ ${ }^{2}$ School of Food Biosciences, University of Reading, Reading RG6 6AP, UK \\ ${ }^{3}$ Culture Collection, Department of Clinical Bacteriology, University of Göteborg, SE-413 46 \\ Göteborg, Sweden \\ ${ }^{4}$ Department of Botany and Microbiology, University of Oklahoma, Norman, OK 73019-0245, \\ USA
}

Two Gram-negative, anaerobic, non-spore-forming, rod-shaped organisms were isolated from a swine-manure storage pit. Based on morphological and biochemical criteria, the strains were tentatively identified as belonging to the genus Bacteroides but they did not appear to correspond to any recognized species of the genus. Comparative $16 \mathrm{~S}$ rRNA gene sequencing studies showed that the strains were related closely to each other and confirmed their placement in the genus Bacteroides, but sequence divergence values of $>10 \%$ from reference Bacteroides species demonstrated that the organisms from manure represent a novel species. Based on biochemical criteria and molecular genetic evidence, it is proposed that the unknown isolates from manure be assigned to a novel species of the genus Bacteroides, as Bacteroides coprosuis sp. nov. The type strain is $\mathrm{PC} 139^{\top}$ (= CCUG $50528^{\top}=$ NRRL B-41113 ${ }^{\top}$ ).
Modern large-scale swine production operations result in the generation of large quantities of manure, which is increasingly being concentrated into smaller localities. Lagoon treatment or under-barn deep-pit storage are among the most favoured methods used for the management of liquid swine manure. Odour emanating from the storage of swine manure can be a cause of considerable nuisance to the public. The odorous chemicals produced (e.g. ammonia, organic acids and alcohols, and sulfides) are largely the result of incomplete digestion processes associated with anaerobic systems (Spoelstra, 1980; Yasuhara \& Fuwa, 1979; Yasuhara et al., 1984; Zahn et al., 1997). There is presently a paucity of data about the types of micro-organisms that reside in stored manure and that are responsible for production of odorous compounds. During the course of an ongoing study into the microbial diversity and antibiotic resistance present within manure storage pits (Cotta et al., 2003; Whitehead \& Cotta, 2001), we characterized two strains of anaerobic, Gram-negative, rod-shaped organisms of uncertain taxonomic position.

Published online ahead of print on 12 August 2005 as DOI 10.1099/ ijs.0.63869-0.

The GenBank/EMBL/DDBJ accession number for the 16S rRNA gene sequence of strain CCUG $50528^{\top}$ is AF319778.
Based on the results of a polyphasic taxonomic study, it is proposed that the isolates be assigned to a novel species of the genus Bacteroides, as Bacteroides coprosuis sp. nov.

Isolates $\mathrm{PC} 139^{\mathrm{T}}$ and $\mathrm{PC} 111$ were recovered from a manure storage pit from a swine facility near Peoria, IL, USA, where the feeder pigs were fed a corn-soybean-based diet. Samples (50-100 ml) from manure storage pits were collected using a Tank Sampler and transferred to Whirl-Pak sampling bags (both NASCO). Samples were kept on ice until return to the laboratory. Isolations and enumerations were performed by plating samples that were serially diluted in anaerobic buffer [RGM medium (see below) with volatile fatty acids, yeast extract and trypticase omitted] onto habitat-simulating media containing either $40 \%(\mathrm{v} / \mathrm{v})$ substrate-depleted rumen fluid (RF medium; Dehority \& Grubb, 1976; Leedle \& Hespell, $1980)$ or $80 \%(\mathrm{v} / \mathrm{v})$ clarified swine-manure slurry [slurry medium; spun at $8000 \mathrm{~g}, 20 \mathrm{~min}, 4^{\circ} \mathrm{C}$ (Cotta et al., 2003)]. The media used in these experiments were prepared anaerobically using the method of Hungate as modified by Bryant (1972). The basic media contained macrominerals, microminerals, buffers, reducing agents and other components as in the routine growth medium (RGM) as described by Hespell et al. (1987) or anaerobic BHI medium as described by Whitehead \& Flint (1995). No additional volatile fatty acids were added to slurry-containing media. Glucose, xylose, 
cellobiose, maltose, starch $(0 \cdot 05 \% \mathrm{w} / \mathrm{v}$ each $)$ and peptone $(0.3 \% \mathrm{w} / \mathrm{v})$ were provided as complex carbon, nitrogen and energy sources. Identical media were prepared containing $10 \mu \mathrm{g}$ tylosin or erythromycin $\mathrm{ml}^{-1}$ to investigate potential resistance to these antibiotics. Plates were incubated anaerobically in a Coy Anaerobic chamber in a $96 \%$ carbon dioxide, $4 \%$ hydrogen atmosphere. Plates were initially incubated at room temperature (approximately $24^{\circ} \mathrm{C}$ ) for manure slurry samples to simulate the pit environment (Cotta et al., 2003). The new isolates were subsequently found to grow equally well at $37^{\circ} \mathrm{C}$. Single colonies were picked and repeatedly streaked out until pure cultures were obtained. For morphological and physiological studies, strains were grown on RGM medium with $0 \cdot 2 \%$ carbohydrate or on BHI medium. For antibiotic testing, suspensions of the bacterial isolates were grown on anaerobic complex medium containing the appropriate antibiotic. The strains were characterized biochemically by using a combination of conventional tests as described previously (Holdeman et al., 1977) and the API Rapid ID32An and API ZYM systems (API bioMérieux) according to the manufacturer's instructions. Absence of spores was determined by visual examination as well as by incubation of the cultures in $95 \%$ ethanol followed by plating onto anaerobic agar medium. Determination of the DNA G $+C$ content was carried out by thermal denaturation of chromosomal DNA using a Beckman model DU 640 spectrophotometer equipped with a highperformance temperature controller and $T_{\mathrm{m}}$ analysis software (Johnson, 1994). 16S rRNA gene fragments were generated by PCR using universal primers $\mathrm{pA}$ (positions 8-28, Escherichia coli numbering) and $\mathrm{pH}^{\star}$ (positions 1542-1522). The amplified products were purified by using a QIAquick PCR purification kit and sequenced directly using primers to conserved regions of the 16S rRNA gene. Sequencing was performed using a PRISM Taq Dyedeoxy Terminator cycle sequencing kit (Applied Biosystems) and an automatic DNA sequencer (model 373A; Applied Biosystems). The closest known relatives of the new isolates were identified by performing database searches using the program FASTA (Pearson \& Lipman, 1988). These sequences and those of other known related strains were retrieved from GenBank and aligned with the newly determined sequence using the program SEQTOOLS (S. W. Rasmussen; http://www.seqtools.dk). The resulting multiple sequence alignment was corrected manually using the program GENEDOC (Nicholas et al., 1997), and a phylogenetic tree was constructed according to the neighbourjoining method (Saitou \& Nei, 1987) with the programs SEQTOOLS and TREEVIEW (Page, 1996); the stability of the groupings was estimated by bootstrap analysis (1000 replications) using the same programs.

Cells of the two isolates originating from pig-manure slurries, $\mathrm{PC} 139^{\mathrm{T}}$ and PC111, were anaerobic, non-sporeforming, non-motile, Gram-negative rods. Typical cells are $0 \cdot 8-3 \cdot 0 \mu \mathrm{m}$ by $0 \cdot 5-1 \cdot 5 \mu \mathrm{m}$ in size. Colonies grown on $\mathrm{BHI}$ agar plates after $48 \mathrm{~h}$ incubation at $37^{\circ} \mathrm{C}$ under $96 \% \mathrm{CO}_{2} /$ $4 \% \mathrm{H}_{2}$ gas phase are cream, circular, convex, entire and opaque and reach a diameter of $1 \mathrm{~mm}$. They hydrolysed aesculin and starch but failed to reduce nitrate to nitrite and were indole-negative. Growth was observed in RGM containing glucose, maltose and chondroitin sulfate, but no growth was obtained with arabinogalactan, arabinose, cellobiose, corn-fibre xylan, corn-spelt xylan, fructose or xylose. Strains grew at temperatures from 25 to $37^{\circ} \mathrm{C}$, but not at 42 or $45^{\circ} \mathrm{C}$, with an optimum of $37^{\circ} \mathrm{C}$. Strains were resistant to $20 \%$ bile. Gelatin was not liquefied. Analysis of the end products of metabolism from $\mathrm{BHI}$ broth revealed acetic acid $(8 \cdot 0-15 \cdot 0 \mathrm{mM})$, succinic acid $(7 \cdot 5-10 \cdot 0 \mathrm{mM})$ and propionic acid $(4 \cdot 0-22 \mathrm{mM})$. Using the API Rapid ID32AN test system, the unknown manure isolates were positive for alkaline phosphatase, alanine arylamidase, arginine arylamidase, $\alpha$-fucosidase, $\beta$-galactosidase, $\beta$-glucosidase, $\alpha$-glucosidase, glutamyl glutamic acid arylamidase, leucyl glycine arylamidase and $N$-acetyl- $\beta$-glucosaminidase, and acid was produced from mannose. All other reactions in this test system were negative. Employing the API ZYM test kit, positive reactions were obtained for $\mathrm{N}$-acetyl- $\beta$-glucosaminidase, alkaline phosphatase, acid phosphatase, $\alpha$-glucosidase and phosphoamidase. All other tests were negative using the API ZYM gallery. Indole was not produced and nitrate was not reduced. Gelatin was not hydrolysed. The quantitative fatty acid profile of $\mathrm{PC} 139^{\mathrm{T}}$ consisted of iso- $\mathrm{C}_{11: 0}(0 \cdot 4 \%)$, anteiso$\mathrm{C}_{11: 0}(0 \cdot 2 \%)$, iso- $\mathrm{C}_{13: 0}(1 \cdot 1 \%)$, anteiso- $\mathrm{C}_{13: 0}(0 \cdot 8 \%), \mathrm{C}_{15: 0}$ $(7 \cdot 6 \%)$, iso- $\mathrm{C}_{15: 0}(8 \cdot 2 \%)$, anteiso- $\mathrm{C}_{15: 0}(31 \cdot 3 \%)$, iso- $\mathrm{C}_{16: 0}$ $(1 \cdot 3 \%), \mathrm{C}_{16: 0}(3 \cdot 5 \%), \mathrm{C}_{16: 1} \omega 7 c(0 \cdot 3 \%), \mathrm{C}_{17: 0}(2 \cdot 2 \%)$, iso- $\mathrm{C}_{17: 0}(10 \cdot 1 \%)$, anteiso- $\mathrm{C}_{17: 0}(3 \cdot 2 \%)$, iso- $\mathrm{C}_{17: 0} 3-\mathrm{OH}$ $(17 \cdot 4 \%)$, anteiso- $\mathrm{C}_{17: 1} \omega 9 c(2 \cdot 2 \%), \mathrm{C}_{18: 0}(1 \cdot 4 \%)$ and $\mathrm{C}_{18: 1} \omega 9 c(2 \cdot 4 \%)$. In addition, the profile also contained a summed feature consisting of $\mathrm{C}_{18: 2} \omega 6,9 c /$ anteiso- $\mathrm{C}_{18: 0}$ $(6 \cdot 36 \%)$. The two isolates were resistant to ampicillin $\left(100 \mu \mathrm{g} \mathrm{ml}^{-1}\right)$, cefoxitin $\left(20 \mu \mathrm{g} \mathrm{ml}^{-1}\right)$, erythromycin $(10 \mu \mathrm{g}$ $\left.\mathrm{ml}^{-1}\right)$, gentamicin $\left(200 \mu \mathrm{g} \mathrm{ml}^{-1}\right)$ and tetracycline $(3 \mu \mathrm{g}$ $\left.\mathrm{ml}^{-1}\right)$. The $\mathrm{G}+\mathrm{C}$ content of the DNA of a representative strain $\left(\mathrm{PC} 39^{\mathrm{T}}\right)$ of the unknown bacterium was $36 \cdot 4 \mathrm{~mol} \%$.

To determine the phylogenetic affiliations between the isolates and to recognized species, the 16S rRNA genes were amplified by PCR and sequenced, yielding a continual stretch of $>1450$ bases. Strains PC139 $9^{\mathrm{T}}$ and PC111 were found to be genetically highly related to each other, displaying $99 \cdot 7 \% 16 \mathrm{~S}$ rRNA gene sequence similarity. Treeing analysis revealed that the isolates were members of the Bacteroides-Prevotella-Porphyromonas rRNA super cluster of organisms (data not shown), and had a specific affinity with members of the genus Bacteroides. The phylogenetic position of $\mathrm{PC} 139^{\mathrm{T}}$ using a reduced dataset is shown in Fig. 1. Treeing analysis clearly showed that this unknown bacterium represents a new subline within the genus Bacteroides. Although the novel organism displayed no phylogenetic affinity with any particular species, displaying $16 \mathrm{~S}$ rRNA gene sequence divergence values of $\geqslant 10 \%$, branching of the unknown organism at the base of this group was supported by a bootstrap resampling value of $100 \%$. There is no precise correlation between percentage 16S rRNA gene sequence divergence and species delineation, but it is generally recognized that divergence values of $\geqslant 3 \%$ 


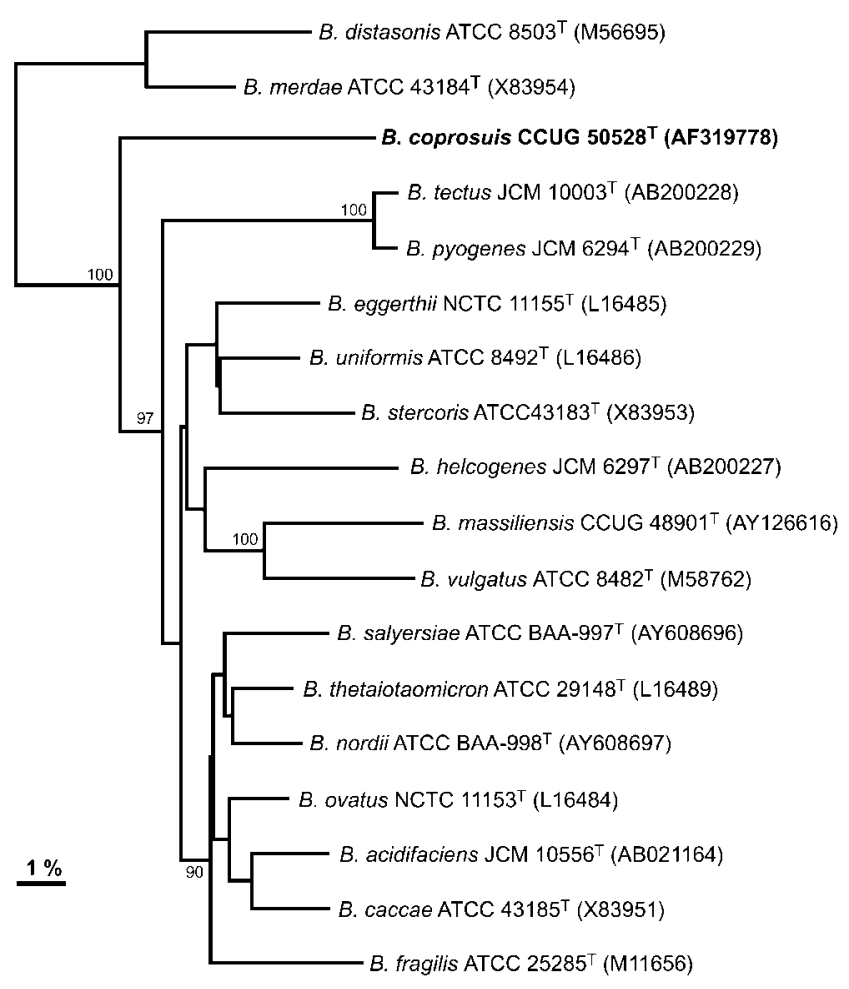

Fig. 1. Unrooted tree showing the phylogenetic interrelationships of Bacteroides coprosuis sp. nov. among its nearest relatives. The tree was constructed by using the neighbour-joining method and is based on a comparison of 1330 nt. Bootstrap values, each expressed as a percentage of 1000 replications, are given at branching points. Bar, $1 \%$ sequence divergence.

are significant (Stackebrandt \& Goebel, 1994). Support for the distinctiveness of the unknown manure bacterium was also evident from phenotypic analyses. Tests that proved useful in distinguishing the novel species from some recognized Bacteroides species are shown in Table 1. Based on the phylogenetic and phenotypic evidence presented, we consider that the two unidentified isolates recovered from pig manure should be assigned to the genus Bacteroides, as Bacteroides coprosuis sp. nov.

\section{Description of Bacteroides coprosuis sp. nov.}

Bacteroides coprosuis (co.pro.su'is. Gr. n. kopros faeces; L. gen. n. suis of a pig; N.L. gen. n. coprosuis from pig faeces, from which the organism was isolated).

Cells are Gram-negative rods that are anaerobic, non-motile and non-spore-forming. Typical cells are $0 \cdot 8-3 \cdot 0 \mu \mathrm{m}$ by $0 \cdot 5-1 \cdot 5 \mu \mathrm{m}$ in size. Colonies grown on $\mathrm{BHI}$ agar plates after $48 \mathrm{~h}$ incubation at $37^{\circ} \mathrm{C}$ under $96 \% \mathrm{CO}_{2} / 4 \% \mathrm{H}_{2}$ gas phase are cream, circular, convex, entire and opaque and reach a diameter of $1 \mathrm{~mm}$. Optimum temperature for growth is $37^{\circ} \mathrm{C}$. Catalase, oxidase and urease are not produced. Gelatin is not liquefied. Growth is observed in RGM containing glucose, maltose and chondroitin sulfate. Acid
Table 1. Biochemical characteristics useful in differentiating Bacteroides coprosuis sp. nov. from some other members of the genus Bacteroides

Species: 1, Bacteroides coprosuis; 2, Bacteroides caccae; 3, Bacteroides eggerthii; 4, Bacteroides fragilis; 5, Bacteroides massiliensis; 6, Bacteroides nordii; 7, Bacteroides ovatus; 8, Bacteroides thetaiotaomicron; 9, Bacteroides salyersiae; 10, Bacteroides stercoris; 11, Bacteroides uniformis; 12, Bacteroides vulgatus. Characteristics are scored as: + , positive; - , negative; $\mathrm{W}$, weak. All data taken from Rapid ID32An tests performed at CCUG (http://www.ccug.gu.se).

\begin{tabular}{|c|c|c|c|c|c|c|c|c|c|c|c|c|}
\hline Characteristic & 1 & 2 & 3 & 4 & 5 & 6 & 7 & 8 & 9 & 10 & 11 & 12 \\
\hline$\alpha$-Galactosidase & $\mathrm{W}$ & + & - & + & + & W & + & + & + & - & + & + \\
\hline$\beta$-Glucosidase & + & + & + & + & - & + & + & + & + & + & + & - \\
\hline Raffinose & - & + & - & + & - & + & + & + & + & + & + & + \\
\hline Indole & - & - & W & - & - & W & + & + & + & + & + & + \\
\hline Arginine arylamidase & + & + & - & + & $\mathrm{W}$ & - & - & + & - & - & - & - \\
\hline Phenyl arylamidase & - & + & - & - & $\mathrm{W}$ & - & - & + & - & - & - & - \\
\hline Leucine arylamidase & - & + & - & + & + & + & + & + & + & + & + & - \\
\hline $\begin{array}{l}\text { Glutamyl glutamic } \\
\text { acid arylamidase }\end{array}$ & - & + & + & + & - & + & $T$ & + & + & + & + & - \\
\hline$\alpha$-Fucosidase & + & + & - & + & + & - & - & + & - & + & - & + \\
\hline Histidine arylamidase & - & W & - & - & $\mathrm{W}$ & - & - & + & - & - & - & - \\
\hline
\end{tabular}

end products of glucose metabolism are acetate, succinate and propionate. Using API kits, a positive reaction is observed from acid phosphatase, $N$-acetyl- $\beta$-glucosaminidase, alkaline phosphatase, alanine arylamidase, arginine arylamidase, chymotrypsin, cystine arylamidase, esterase $\mathrm{C} 4$, ester lipase C8, $\alpha$-fucosidase, $\beta$-galactosidase, $\beta$-glucosidase, $\alpha$ glucosidase, glutamyl glutamic acid arylamidase, leucyl glycine arylamidase, lipase C14 and mannose. Activity is not detected for $\alpha$-arabinosidase, arginine dihydrolase, $\alpha$-fucosidase, $\beta$ galactosidase-6-phosphate, $\beta$-glucuronidase, glutamic acid arylamidase, glycine arylamidase, histidine arylamidase, leucine arylamidase, $\alpha$-mannosidase, phenyl alanine arylamidase, proline arylamidase, phosphoamidase, pyroglutamic acid arylamidase, raffinose, serine arylamidase, tyrosine arylamidase, trypsin or valine arylamidase. Aesculin and starch are hydrolysed. Indole is not produced. Nitrate is not reduced. Gelatin is not hydrolysed. Resistant to ampicillin $\left(100 \mu \mathrm{g} \mathrm{ml}^{-1}\right)$, cefoxitin $\left(20 \mu \mathrm{g} \mathrm{ml}^{-1}\right)$, erythromycin $\left(10 \mu \mathrm{g} \mathrm{ml}^{-1}\right)$, gentamicin $\left(200 \mu \mathrm{g} \mathrm{ml}^{-1}\right)$ and tetracycline $\left(3 \mu \mathrm{g} \mathrm{ml}^{-1}\right)$. The major long-chain cellular fatty acids present are $\mathrm{C}_{15: 0}$, iso- $\mathrm{C}_{15: 0}$, anteiso- $\mathrm{C}_{15: 0}, \mathrm{C}_{16: 0}$, iso- $\mathrm{C}_{17: 0}$ and anteiso- $\mathrm{C}_{17: 0}$.

The type strain, PC139 ${ }^{\mathrm{T}}\left(=\mathrm{CCUG} 50528^{\mathrm{T}}=\mathrm{NRRL}\right.$ B$41113^{\mathrm{T}}$ ), was isolated from swine manure. The DNA G $+\mathrm{C}$ content of the type strain is $36 \cdot 4 \mathrm{~mol} \%$.

\section{Acknowledgements}

The authors wish to acknowledge the excellent technical assistance of Rhonda Zeltwanger. Product names are necessary to report factually on available data; however, the USDA neither guarantees nor warrants the 
standard of the product, and the use of the name by the USDA implies no approval of the product to the exclusion of others that may also be suitable.

\section{References}

Bryant, M. P. (1972). Commentary on the Hungate technique for culture of anaerobic bacteria. Am J Clin Nutr 25, 1324-1328.

Cotta, M. A., Whitehead, T. R. \& Zeltwanger, R. L. (2003). Isolation, characterization and comparison of bacteria from swine faeces and manure storage pits. Environ Microbiol 5, 737-745.

Dehority, B. A. \& Grubb, J. A. (1976). Basal medium for the selective enumeration of rumen bacteria utilizing specific energy sources. Appl Environ Microbiol 32, 703-710.

Hespell, R. B., Wolf, R. \& Bothast, R. J. (1987). Fermentation of xylans by Butyrivibrio fibrisolvens and other ruminal bacteria. Appl Environ Microbiol 53, 2849-2853.

Holdeman, L. V., Cato, E. P. \& Moore, W. E. C. (1977). Anaerobe Laboratory Manual, 4th edn. Blacksburg, VA: Virginia Polytechnic Institute \& State University.

Johnson, J. L. (1994). Similarity analysis of DNAs. In Methods for General and Molecular Bacteriology, pp. 656-682. Edited by P. Gerhardt, R. G. E. Murray, W. A. Wood \& N. R. Krieg. Washington, DC: American Society for Microbiology.

Leedle, J. A. Z. \& Hespell, R. B. (1980). Differential carbohydrate media and anaerobic replica plating techniques in delineating carbohydrate-utilizing subgroups in rumen bacterial populations. Appl Environ Microbiol 39, 709-719.

Nicholas, K. B., Nicholas, H. B., Jr \& Deerfield, D. W., II (1997). GENEDOC: analysis and visualization of genetic variation. EMBNEW News 4, 14.
Page, R. D. M. (1996). TreeView: an application to display phylogenetic trees on personal computers. Comput Appl Biosci 12, 357-358.

Pearson, W. \& Lipman, D. (1988). Improved tools for biological sequence comparison. Proc Natl Acad Sci U S A 85, 2444-2448.

Saitou, N. \& Nei, M. (1987). The neighbor-joining method: a new method for reconstructing phylogenetic trees. Mol Biol Evol 4, 406-425.

Spoelstra, S. F. (1980). Origin of objectionable odorous components in piggery wastes and the possibility of applying indicator components for studying odour development. Agric Environ 5, 241-260.

Stackebrandt, E. \& Goebel, B. M. (1994). Taxonomic note: a place for DNA-DNA reassociation and 16S rRNA sequence analysis in the present species definition in bacteriology. Int J Syst Bacteriol 44, 846-849.

Whitehead, T. R. \& Cotta, M. A. (2001). Characterisation and comparison of microbial populations in swine faeces and manure storage pits by $16 \mathrm{~S}$ rDNA gene sequence analysis. Anaerobe 7, 181-187.

Whitehead, T. R. \& Flint, H. J. (1995). Heterologous expression of an endoglucanase gene (endA) from the ruminal anaerobe Ruminococcus flavefaciens 17 in Streptococcus bovis and Streptococcus sanguis. FEMS Microbiol Lett 126, 165-169.

Yasuhara, A. \& Fuwa, K. (1979). Volatile and odorous components in solid swine manure. Agric Biol Chem 43, 313-316.

Yasuhara, A., Fuwa, K. \& Jimbu, M. (1984). Identification of odorous compounds in fresh and rotten swine manure. Agric Biol Chem 48, 3001-3010.

Zahn, J. A., Hatfield, J. L., Do, Y. S., DiSpirito, A. A., Laird, D. A. \& Pfeiffer, R. L. (1997). Characterization of volatile organic emissions and wastes from swine production facilities. J Environ Qual 26, $1687-1696$. 